\title{
ANEMIA FALCIFORME E SEUS ASPECTOS PSICOSSOCIAIS: O OLHAR DO DOENTE E DO CUIDADOR FAMILIAR ${ }^{1}$
}

\author{
ENFERMEDAD DE CÉLULAS FALCIFORMES Y SUS ASPECTOS PSICOSOCIALES: \\ LA MIRADA DEL PACIENTE Y DEL CUIDADOR FAMILIAR \\ SICKLE CELL DISEASE AND ITS PSYCHOSOCIAL ASPECTS: \\ THE LOOK OF PATIENT AND CAREGIVER FAMILY \\ Hélide Damille Silva ${ }^{2}$, Gilvânia Patrícia do Nascimento Paixão ${ }^{3}$, Cristiane dos Santos Silva ${ }^{4}$, \\ Isaiane Santos Bittencourt ${ }^{5}$, Taiana Jambeiro Evangelista ${ }^{6}$, Rudval Souza da Silva ${ }^{7}$
}

\section{RESUMO}

Introdução: A Anemia Falciforme é uma doença genética e hereditária caracterizada por anemia hemolítica crônica e crises vaso-oclusivas agudas ocasionando lesões nos tecidos e órgãos de maneira progressiva. No Brasil, é uma das doenças genética e hereditária mais prevalente e que ocorre, principalmente, nos afrodescendentes, devido à herança genética africana, por se tratar de uma doença originária na África. Materiais e Métodos: Pesquisa exploratória descritiva com abordagem qualitativa, realizada num município a 197 km de Salvador, Bahia, Brasil, capital do Estado. Participaram do estudo dez pessoas, das quais cinco eram pacientes com doença falciforme e cinco familiares. A coleta de dados ocorreu nos meses de julho e agosto de 2012, com a realização de entrevista semiestruturada com o uso de gravador. A análise dos dados se deu a parti da Técnica de Análise de Conteúdo proposta por Bardin. Resultados: Da análise emergiram quatro categorias, a saber: sentimentos relacionados à condição crônica da doença; relações sociais; vivendo com a anemia falciforme e suas limitações; conhecimento dos familiares sobre anemia falciforme. Discussão e Conclusões: Os portadores demonstraram a presença de obstáculos de natureza psicossocial, que somados com a condição crônica da doença, alteram sua qualidade de vida. Além de que, evidenciou-se que os fatores sociais e econômicos interferem na sua qualidade de vida, sendo o desemprego um dos fatores mais impactante, contribuindo negativamente para a insatisfação em relação a sua qualidade de vida. Conluiese que se faz necessária a (re) construção de medidas efetivas para o controle de desordens psicossociais que interferem negativamente na qualidade de vida dos portadores de anemia falciforme. (Rev Cuid 2013; 4(1): 475-83).

Palavras chave: Anemia Falciforme, Cuidadores, Grupo Social, Estigma Social. (Fonte: DeCS BIREME).

\section{RESUMEN}

Introducción: La anemia falciforme es una enfermedad genética y hereditaria que se caracteriza por una anemia hemolítica crónica y las crisis vaso-oclusivas que causan daño a los tejidos y órganos agudos progresivos. En Brasil, es una de las enfermedades genéticas y hereditarias más frecuentes y afecta principalmente a afrodescendientes, debido a que es una enfermedad originaria de África. Materiales y Métodos: Estudio descriptivo exploratorio con abordaje cualitativo, realizado en un municipio a 197 kilómetros de Salvador, Bahía, Brasil, la capital del estado. El estudio incluyó a diez personas, entre ellas cinco pacientes con enfermedad de células falciformes y cinco miembros de la familia. Los datos fueron recolectados durante los meses de julio y agosto de

\footnotetext{
Artigo Original.

2 Enfermeira, Graduada Pela Universidade do Estado da Bahia-UNEB/Campus VII - Senhor do Bonfim, Bahia, Brasil.

3 Enfermeira, Mestre em Enfermagem, Professora Auxiliar da Universidade do Estado da Bahia - UNEB/Campus VII - Senhor do Bonfim, Bahia, Brasil.

4 Enfermeira, Mestre em Enfermagem, Enfermeira Assistencial do Hospital Clériston Andrade - Feira de Santana, Bahia, Brasil.

5 Enfermeira, Mestre em Enfermagem, Professora Assistente da Universidade do Estado da Bahia - UNEB/Campus VII - Senhor do Bonfim, Bahia, Brasil.

${ }^{6}$ Acadêmica do Curso de Enfermagem da Universidade do Estado da Bahia - UNEB/Campus VII - Senhor do Bonfim, Bahia, Brasil.

7 Enfermeiro, Mestre e Doutorando em Enfermagem, Bolsista CAPES, Professor Assistente da Universidade do Estado da BahiaUNEB/Campus VII - Senhor do Bonfim, Bahia, Brasil. Autor de Correspondente: Rudval Souza da Silva. Universidade do Estado da Bahia Departamento de Educação - Campus VII. Rodovia Lomanto Júnior, BR 407, Km 127 CEP: 48970-000 Senhor do Bonfim (BA). Brasil. E-mail: rudvalsouza@yahoo.com.br Articulo recibido el 02 de Junio de 2013 y aceptado para su publicación el 30 de Julio de 2013.
} 
2012, con la realización de entrevista semi-estructurada con el uso de una grabadora. El análisis de los datos fue mediante la técnica de Análisis de Contenido propuesta por Bardin. Resultados: Cuatro categorías surgieron del análisis: sentimientos relacionados a la condición de enfermedad crónica; las relaciones sociales; viviendo con anemia de células falciformes y sus limitaciones; conocimiento de los familiares de la anemia de células falciformes. Discusión y Conclusiones: Los pacientes mostraron la presencia de obstáculos de naturaleza psicosocial, lo que unido a la condición crónica, alteran su calidad de vida. Además, se evidenció que los factores sociales y económicos influyen en su calidad de vida, siendo el desempleo, uno de los más impactantes, contribuyendo negativamente a la insatisfacción en relación a su calidad de vida. Se concluye que es necesaria la reconstrucción de medidas efectivas para el control de trastornos psicosociales que inciden negativamente en la calidad de vida de los pacientes con anemia de células falciformes.

Palabras clave: Anemia de Células Falciformes, Cuidadores, Grupo Social, Estigma Social. (Fuente: DeCS BIREME).

\section{ABSTRACT}

Introduction: Sickle Cell Anemia is a genetic and inherited disorder characterized by chronic hemolytic anemia and vaso-occlusive crises causing acute tissue damage and organ progressively. In Brazil, it is a genetic disease and most prevalent hereditary and occurs primarily in African descent due to African genetic heritage, because it is a disease originating in Africa. Materials and Methods: A descriptive exploratory research with a qualitative approach, carried out in the municipality $197 \mathrm{~km}$ from Salvador, Bahia, Brazil, the state capital. The study included ten people, including five patients with sickle cell disease and five family members. Data collection occurred during the months of July and August 2012, with the completion of semistructured interview with a tape recorder. The analysis of data was left of the Technical Content Analysis proposed by Bardin (2009). Results: Four categories emerged from the analysis namely: feelings related to the condition of chronic disease; social relations; living with sickle cell anemia and its limitations; knowledge of family members of sickle cell anemia. Discussion and Conclusions: The patients showed the presence of psychosocial obstacles, which together with the chronic condition, change their quality of life. Besides that, it became clear that the social and economic factors influence the quality of life, unemployment being one of the most impactful, contributing negatively to dissatisfaction with their quality of life. Conluie that it is necessary to (re) construction of effective measures for the control of psychosocial disorders that adversely affect the quality of life of patients with sickle cell anemia.

Key words: Anemia Sickle Cell, Caregivers, Social Group, Social Stigma. (Source: DeCS BIREME).

\section{INTRODUÇÃO}

A Anemia Falciforme (AF) é uma doença genética e hereditária caracterizada por anemia hemolítica crônica e crises vaso-oclusivas (CVO) agudas ocasionando lesões nos tecidos e órgãos de maneira progressiva. As hemoglobinopatias, e mais especificamente a anemia falciforme, trazem muitos riscos e prejuízos na vida dos doentes, fortalecendo a necessidade de uma maior atenção no ponto de vista médico, da enfermagem, genético e psicossocial (1).

Na realidade brasileira, a AF é considerada como a doença genética e hereditária mais prevalente, em especial dentre os afrodescendentes, haja vista sua característica de herança genética africana, por tratar-se de uma doença originária na África. Os maiores índices concentram-se na Bahia, onde em cada 650 nascidos vivos, um possui algum tipo de doença falciforme (2). O gene "S" se distribuí de forma heterogênea estimando-se para cada mil nascidos vivos uma criança com AF (3). As regiões do Brasil com maior prevalência são Norte e Nordeste por ter grande influência da raça negra em sua população (4). Mais especificamente no Nordeste, a prevalência do gene é de $3 \%$, alcançando $5,5 \%$ no Estado da Bahia (5).

Tratando-se de uma doença crônica e, levando-se em consideração de que a medida da qualidade de vida pode influenciar diretamente no prognóstico da doença, a AF pode ser considerada como um problema de Saúde Pública. O que revela a necessidade de estudos acerca de estratégias para implementar programas de saúde e privilegiar ações de cuidado as pessoas com a doença (6).

O mecanismo fisiopatológico principal da $\mathrm{AF}$ é o processo de crises vaso-oclusivas que acomete a microcirculação de maneira sistêmica e é responsável por alta morbimortalidade na infância. As pessoas que convivem constantemente com a $\mathrm{AF}$, tem manifestações clínicas de anemia crônica e episódios sequenciais de CVO, com dores intensas e recorrentes, as quais respondem pelas diversas complicações da doença (7).

Os aspectos psicossociais frente a uma doença crônica devem ser percebidos e analisados cuidadosamente, já que influencia a autoestima, a formação da personalidade, as defesas, as relações familiares e sociais de cada pessoa. Essas alterações corroboram para um caminho de má Qualidade de Vida dos sujeitos com doença incurável como a $\mathrm{AF}(1)$.

Existem algumas estratégias de políticas públicas, do governo brasileiro, voltadas para a população com algum tipo de hemonoglobinopatia. No entanto, a invisibilidade ainda presente, não permite que as leis acolham as pessoas com AF, preservando os princípios e diretrizes do Sistema Único de Saúde (SUS), o que acaba por aumentar a exclusão dessas pessoas numa condição de abandono social (2). 
Segundo estudos (8) acerca da epidemiologia da AF "a literatura existente no Brasil fornece pouca informação acerca do comportamento da doença falciforme, em seus diversos aspectos". Com vistas a melhorar a qualidade de vida dos portadores de AF é preciso um planejamento de ações eficazes em diversas áreas da saúde, o que tornam indispensáveis estudos mais aprofundados sobre os aspectos psicossociais característicos desse grupo de pessoas. Para tal precisa-se compreender o meio em que vive o portador da $\mathrm{AF}$, suas condições de escolaridade, trabalho e seguridade social, para evitar uma visão restrita da doença e, consequentes soluções pouco eficazes (9).

Nesta perspectiva, a relação dos aspectos psicossociais com a qualidade de vida destas pessoas, pode colaborar para o desenvolvimento de ações que minimizem os impactos negativos em seus relacionamentos na família, na escola, no trabalho e na comunidade. Esses indivíduos encontram dificuldades, as quais envolvem vários aspectos importantes que interferem no convívio em comunidade por ser uma doença ainda invisível pela maior parte da população, por não ter esclarecimentos que possibilitem a desconstrução de estigmas em relação à doença e, principalmente por vir acompanhada do preconceito e discriminação racial, elementos que implicam negativamente nas condições de viver, adoecer e morrer das pessoas com doença falciforme.

Assim, a inclusão dos familiares cuidadores é imprescindível para análise da qualidade de vida das pessoas com anemia falciforme por ser uma doença que requer um cuidado intenso e de entrega dos envolvidos para prevenir complicações e manter um quadro clínico estável. Para tanto é indispensável o envolvimento da família, considerando que esta convive desde a fase do diagnóstico, alterando suas rotinas e direcionando sua atenção para o filho doente (5).

Tomando por base a contextualização acerca das implicações da anemia falciforme na qualidade de vida das pessoas portadoras da doença, o presente estudo teve como objetivo analisar a interferência dos aspectos psicossociais no nível de qualidade de vida dos portadores de anemia falciforme e de seus familiares cuidadores.

\section{MATERIAIS E MÉTODOS}

Trata-se de pesquisa de campo, exploratória e descritiva com abordagem qualitativa, realizada no município de Riachão do Jacuípe - BA, distante 197 km de Salvador, Bahia, Brasil, capital do Estado. A população atual do município de Riachão do Jacuípe é de 33.172 habitantes, segundo o Censo 2010 realizado pelo Instituto Brasileiro de Geografia e Estatística (10), distribuídas entre brancos, negros e descendentes de índios Tocoiós.

Os participantes da pesquisa foram recrutados através de busca ativa no próprio município em parceria com a Secretaria Municipal de Saúde, as Unidades Básicas de Saúde e o Programa de Agentes Comunitários de Saúde (PACS), atendendo-se aos seguintes critérios de inclusão: pessoas com diagnóstico de anemia falciforme com idade mínima de 18 anos, residentes na sede do município e contando com um familiar como cuidador, ambos moradores no mesmo domicílio.

Participaram do estudo dez pessoas, obedecendo ao critério de saturação das respostas. Destas, cinco tinham diagnóstico de doença falciforme e as outras cinco eram familiares cuidadores. Todas com idade igual ou superior a 18 anos e diagnóstico confirmado de doença falciforme, cadastradas na Secretaria Municipal de Saúde. Os sujeitos que concordaram em participar do estudo, após os devidos esclarecimentos e atendendo os princípios éticos da Resolução 196/96 do Conselho Nacional de Saúde/Ministério da Saúde, que trata da pesquisa com seres humanos, assinaram o Termo de Consentimento Livre e Esclarecido.

A coleta de dados ocorreu entre os meses de julho e agosto de 2012. Realizou-se entrevistas gravadas, por meio de roteiro semiestruturado contendo perguntas abertas e fechadas com a finalidade de caracterização sociodemográficas dos participantes e para coleta do material empírico. A análise dos dados foi concretizada a partir das falas dos entrevistados, utilizando-se da técnica de Análise de Conteúdo proposta por Bardin (11).

Esta pesquisa respeitou os princípios da beneficência e não maleficência, de modo que o projeto de pesquisa foi submetido ao Comitê de Ética e Pesquisa da Universidade do Estado da Bahia - CEP/UNEB, sendo apreciado e aprovado sob parecer número 64907/2012. Para resguardar o sigilo, foram utilizados nomes fictícios para representar os participantes, sendo assim denominados: as pessoas com $\mathrm{AF}$ foram identificadas por nomes de animais e os familiares cuidadores com nomes de frutas.

\section{RESULTADOS E DISCUSSÕES}

As características sociodemográficas referentes aos portadores de AF que participaram da pesquisa demostraram que a maioria dos participantes era homens, o que pode ser atribuído ao pequeno tamanho da amostra; a idade está compreendida entre 18 e 26 anos, o que demonstra uma baixa expectativa de vida no contexto da população estudada. Os estudos (12), apontam que a média da idade em relação as taxas de mortalidade por AF foi de 26,5 na Bahia, 31,5 anos no Rio de Janeiro e 30 anos em São Paulo. Pesquisas sobre expectativa de vida dos falcêmicos, apesar de um aumento gradativo, ainda demonstram pequenos percentuais acima de $40 \mathrm{ou}$ 50 anos (13).

Em relação à cor/raça notamos que todos os participantes são afrodescendentes, o que permite constatar que a anemia falciforme apesar da miscigenação brasileira, ainda é uma doença de cunho racial e que afeta em 
índices maiores à raça negra (pretos e pardos) devido à herança genética desse grupo populacional, embora também esteja presente na raça branca. As pesquisas 6, têm demonstrado que há uma estreita relação entre a anemia falciforme e a raça negra, valendo ressaltar o duplo caráter estigmatizante por ser uma doença crônica e de origem étnica. Apresenta maior incidência nas regiões norte e nordeste (6\% a 10\%) devido origem negroide na constituição de sua população (14).

Em relação ao estado civil dos portadores desse tipo de anemia, a maioria é de casados ou em união estável e possui relação de dependência com os pais, já que mesmo morando com a esposa, continuam na mesma casa de seus familiares.

Correlacionando os dados de escolaridade e o trabalho remunerado, ressaltamos a convergência do nível de estudo com a situação de trabalho na qual se encontram os entrevistados, visto que foi encontrado que apenas um trabalha com remuneração. Tal assertiva pode estar relacionada a questões limitantes impostas pela doença, como as crises álgicas as quais, em sua maioria, requerem internações e consequente alteração do desenvolvimento das atividades da vida diária.

Estudos (13) sinalizam que cerca de $80 \%$ a $85 \%$ das pessoas com AF são de baixa escolaridade, e que este fator reflete em desemprego na fase adulta, ou baixa remuneração. Dados (15) do Ministério da Saúde do Brasil reafirmam esta situação ao afirmar que as manifestações psicológicas da doença crônica são agravadas pela condição socioeconômica desfavorável para maioria dos pacientes com doença falciforme trazendo muitas dificuldades, principalmente na escola e no trabalho.

Em relação aos familiares dos portadores, dentre todos os participantes eram do sexo feminino, com idade compreendida entre 30 e 62 anos. Todas pertencem à raça negra, já que se autodeclararam de cor parda. Referente ao estado civil, a maioria das cuidadoras é solteira e somente duas são casadas. Dentre estas, três possuem o ensino médio completo, as outras duas, uma tem ensino médio incompleto e a outra fundamental incompleto. A maior parte dos familiares trabalha com remuneração, no entanto a renda mensal não chega a dois salários mínimos.

Em relação ao achado de que a totalidade das cuidadoras é do sexo feminino, pode-se evidenciar que as mulheres são em geral, as responsáveis pelos cuidados com os pacientes de AF. Esse cuidado se revela de maneira intensa, exige tempo disponível e dedicação, que muitas vezes é sobrecarregado e obrigado a abandonar o trabalho fora de casa, para promover atenção exclusiva ao doente. Essa circunstância compromete diretamente a situação financeira da família.

Um estudo (5) revela que a maioria dos responsáveis pelo familiar com doença crônica não trabalha fora de casa por dispensar atenção e tempo cuidando do doente. A mulher culturalmente tem outras obrigações domésticas além de atividades externas e encontram-se sobrecarregadas com as responsabilidades, principalmente quando são sozinhas e não encontram apoio.

Da análise das falas dos entrevistados, emergiram quatro categorias centrais, a saber: Sentimentos relacionados à condição crônica da doença; Relações sociais; Vivendo com a anemia falciforme e suas limitações e, Conhecimentos dos familiares sobre a anemia falciforme. As quais serão apresentadas e discutidas a partir de agora.

\section{Sentimentos Relacionados à Condição Crônica da Doença}

Nesta categoria, foram abordados os sentimentos emanados das falas dos portadores de Anemia Falciforme, dos quais se percebe sentimentos de tristeza, indiferença, angústia, impotência e sensação de inutilidade como descrito nas falas abaixo:

É muito difícil, né? A gente não tem a liberdade que, quem é sadio tem. Não pode pegar peso, fazer o que gosta. (Gato)

Eu me sinto normal. No momento, estou bem, é, mas logo no princípio me sentia indiferente, sentia muitas dores, não podia fazer tudo que as outras pessoas normais fazia porque, não podia tomar banho de água parada que gostava muito. Mas quando entrava sentia muitas dores fortes, mas não sabia o meu problema, o que era, fui descobrir lá pelos 12 anos de idade, meu problema. (Leopardo).

Em um estudo (16) sobre as crises dolorosas da doença falciforme enfocando as abordagens terapêuticas das CVO nos pacientes com AF, relata a percepção de intenso sofrimento diante do estigma da doença, limitações cotidianas, perda da capacidade de trabalho e sentimento de inutilidade. Em pesquisa realizada na cidade de Uberaba com 47 pacientes portadores de doença falciforme, maiores de 18 anos, assim como corroborado pelo estudo (13) que observou os sentimentos de revolta e tristeza em mais de um terço dos participantes e que estão associados ao maior número de crises álgicas por ano.

Um dos participantes, apesar de afirmar que se sente normal diante da doença, revelou angustia em lembrase da época que antecedeu o diagnóstico da patologia. Esta experiência confirma a importância do diagnóstico precoce como indica a Portaria $\mathrm{n}^{\circ} 822$ do Ministério da Saúde do Brasil (17) através do teste do pezinho, como medida fundamental para um acompanhamento multiprofissional e tratamento médico mais direcionado evitando-se sofrimento para os familiares e maiores complicações para o portador de AF.

Neste contexto, as pesquisa (18-19) reafirmam que o diagnóstico precoce, em qualquer doença genética, 
viabiliza medidas preventivas e tratamento específico o quanto antes. Ainda sinalizam que a descoberta da AF através do teste do pezinho, somada à atuação de profissionais capacitados, o apoio da família e comunidade pode intervir de modo a reduzir a morbimortalidade e prevenir complicações clínicas e sequelas e ainda contribui positivamente por possibilitar o acompanhamento clínico e suporte emocional para os pais e filhos afetados, oferecendo esclarecimentos sobre a real situação de saúde e explicando os devidos cuidados a serem tomados diariamente. A maioria revelou aceitação da doença crônica como se verifica nos trechos a seguir:

Me sinto bem! É, assim, tem nada de mais que possa esconder isso né? Só isso. (Coelho)

Me sinto bem! Apesar de ter o problema da anemia, mas me sinto bem. (Borboleta)

O sentimento de aceitação por ser portador de uma doença crônica foi relatado por $38,3 \%$ dos pacientes, o que corresponde a maioria em estudos (13) sobre os aspectos epidemiológicos e sociais da doença. Este tipo de postura não condiz com outros estudos (5-21) ao relatarem que os pacientes com $\mathrm{AF}$ apresentam, normalmente, sintomas de ansiedade e depressão agravados com o preconceito racial e institucional presentes em sua vida, as periódicas crises álgicas e internações e as diversas complicações que podem se manifestar.

\section{Relações Sociais}

A habilidade em enfrentar a doença sem transtornos significativos para sua qualidade de vida pode ser atribuída ao apoio familiar e dos amigos como se percebe nos depoimentos dos participantes (pacientes e familiares) quando relatam sobre suas relações interpessoais:

Pra mim, eu não tenho o que dizer dele, apesar dele ser doente, mas pra mim é sossegado, tem nada de anormal ta entendendo? Ele é normal, agora só que a gente sofre junto com a doença, porque em setembro eu entrei sai em dezembro do ano passado. Ai o tanto que ele tiver no hospital eu to também. (Pêra).

A relação com meus amigos é normal. Não me tratam diferente, muitos até ficam surpreso quando eu falo que sou portador de anemia falciforme, que não parece que eu tenho esse problema. Eu sei evitar coisas que leve os sintomas. (Leopardo).

$\mathrm{O}$ portador de AF pode encarar de diversas formas as possíveis dificuldades e limitações provocadas pela doença e ter uma capacidade de superá-las sem grandes repercussões psicológicas e sociais. Isso não significa que o indivíduo permanecerá isento de crises, porém possui habilidades de suportar com maior disposição (20). Pode ser que a maioria dos sujeitos desse estudo represente as características descritas, mesmo com algumas complicações já instaladas, como úlceras em membros inferiores, Acidente Vascular Cerebral isquêmico (AVC-I) com sequelas (deficiência em membro superior) e infecções constantes.

Mesmo com uma doença hereditária e incurável percebeu-se neste estudo que a relação dos portadores de AF com seus amigos e familiares não sofreu alterações negativas relevantes que prejudicasse sua qualidade de vida. As pesquisas (13) corroboram o presente estudo, ao verificar que $87,3 \%$ dos entrevistados não perceberam mudanças desagradáveis no relacionamento com os amigos e família (78,7\%), porém $31,9 \%$ comentaram que houve alterações para pior em relação ao lazer quando questionados sobre mudanças comportamentais após o diagnóstico da doença.

O depoimento abaixo revela sensação de impotência e desconforto diante de situações específicas do dia-a-dia, como em momentos de lazer com os amigos:

A relação com meus amigos é normal, mas sempre é, fica um pouco difícil né? Eu vejo os outros fazer as coisas e eu não posso fazer. Eles não me tratam diferente, é a merma coisa, mas é comigo mermo que a dificuldade pesa mermo! (Gato).

Aqui é possível perceber que existem situações que são restritivas pela própria evolução da doença, já que, às vezes, não se consegue fazer o que gostaria. Desse modo, há um receio em aceitar tal restrição e recuar diante de alguma dificuldade. Nesta perspectiva, enfatiza-se que o aspecto psicológico deve ser explorado de maneira que, pais e portadores sejam devidamente esclarecidos durante todo processo da doença e tenham apoio para encarar melhor e viver com mais qualidade (20).

\section{Vivendo com a Anemia Falciforme e Suas Limitações}

Essa categoria agrupa os principais problemas e restrições enfrentados pelos doentes, os quais também são apontados pelos seus familiares. Em suas falas podese observar que enfocam diversas facetas relacionadas com a dificuldade de acesso para dar continuidade ao tratamento, a sintomatologia característica da AF, complicações e sequelas provocadas pela evolução crônica da doença, discriminação racial e institucional, desemprego e dificuldades financeiras.

\subsection{Acessibilidade no Tratamento}

Os trechos a seguir expressam as dificuldades que os portadores enfrentam para realizarem o tratamento e assim poderem controlar a evolução da doença:

É ir, minha fia, é ir pra Salvador mais ela pro hospital. A gente tem que sair daqui 3 horas da manhã no carro da saúde aí passa o dia todo lá, quando a gente sai de lá já é de noite. (Uva).

É em relação à saúde mesmo né? Porque não tem um 
plano de saúde bom, não tem como ter, e as vezes ele sofre muito por causa disso também. (Morango).

Uma vez diagnosticado como portador de AF, eles precisam de acompanhamento multiprofissional por toda sua vida, já que é uma doença crônica e incurável. O tratamento deve ser feito de maneira adequada e de acordo com as particularidades de cada indivíduo, pois a patologia tem variedades quanto à sintomatologia e gravidade.

O acompanhamento é realizado em unidades de referência, as quais possuem profissionais capacitados para cuidarem desses pacientes. Como em Riachão do Jacuípe-Ba, não possui essas unidades especializadas, os pacientes são obrigados a se deslocarem periodicamente para a unidade mais próxima que fica na cidade de Salvador, capital do Estado. As consultas e tratamento são constantes e é por esse motivo que as viagens tornamse exaustivas revelando-se como fator estressante para os familiares acompanhantes e para os doentes, os quais já estão comprometidos pela própria natureza da patologia. O baixo nível econômico característico na maioria dos brasileiros com AF, o que os tornam mais dependentes dos serviços públicos de assistência à saúde acrescentando que essa condição financeira desfavorável associada com a dificuldade de encontrar emprego são as principais causas do aparecimento de sintomas depressivos nos adultos (22).

\subsection{A Dor como Sintoma Impactante na Vida dos Doentes}

Os portadores revelaram que as dores são sintomas marcantes em suas vidas, intensas, muitas vezes persistentes e que restringem bastante seu cotidiano, como se pode observar a seguir:

É, não, assim, dores. As dores quando vem ataca os nervos, e a gente para se locomover dói muito, senti muita câimbra, se faz algum esforço acima do normal, como correr, ai ela fica irritada. (Leopardo).

\section{É tentar fazer as coisas e não consegui. (Gato).}

As dores, porque toma remédio e tudo, só passa naquela hora depois torna retorna. (Pêra).

As crises vaso-oclusivas são os eventos que mais acometem os portadores de AF e são responsáveis pela maioria das internações desses pacientes. A dor, de intensidade variável, é o sintoma característico provocado pelo infarto da microcirculação provocado pelo afoiçamento das hemácias. Pode aparecer sem causa aparente ou após exposição a diversos condicionantes como, temperaturas extremas, estresse, esforço físico, desidratação e vários outros (8).

A CVO se configura como a principal causa de morbidade em todos os pacientes. A procura por serviços de emergência e admissão hospitalar é frequente e as crises álgicas são os principais motivos de internações (8). Ela pode aparecer também devido esfriamento súbito da pele, exposição a estresse físico ou emocional (16). A crise dolorosa, identificada num determinado estudo (12) evidenciou que esta correspondeu a causa de $64,4 \%$ dos atendimentos no Hemocentro Regional de Minas Gerais e 36,7\% das internações. A maioria das internações ocorre em jovens, evidenciando o impacto social da patologia e intensifica a importância de otimizar a assistência aos portadores de $\mathrm{AF}(8)$.

\subsection{Complicações e Sequelas}

Através dos depoimentos dos participantes percebeuse que com a progressão da doença, os portadores e seus familiares sofrem com as complicações existentes devido à repercussão que causam em suas vidas. Os trechos abaixo demonstram a dificuldade de conviver com estas manifestações:

Da última vez mermo ele operou em três lugar. [...] Aí ele operou em três partes do corpo virilha, joelho e cotovelo, ajuntou pus, aí agora ele ficou no isolamento lá no Subúrbio e aí demorou mais por causa que o braço não cicatrizava saia pus direto. (Pêra).

Devido o problema a cicatrização fica muito difícil de sarar os ferimentos. (Leopardo).

\section{O meu braço, eu tenho vergonha dele! (Arara azul).}

Outras complicações podem acometer os falcêmicos devido aos infartos agudos ou crônicos na microcirculação. Estes pacientes são mais suscetíveis a infecções e a realizarem procedimentos cirúrgicos. Frequentemente desenvolvem úlceras em membros inferiores cujo tratamento é difícil e a cicatrização é lenta e ainda aumentam o risco de infecção (8).

As infecções também são complicações que geralmente acometem os indivíduos com AF e por muitas vezes são submetidos a procedimentos cirúrgicos ao longo de sua vida (19-24). Num determinado estudo (25) que pesquisou a relação da anemia falciforme e infecções, observou-se que os pacientes com AF possuem um risco 25 vezes maior de desenvolver infecções por salmonelas, principalmente crianças maiores e adultos.

As úlceras de membros inferiores (MMII) podem aparecer com frequência em adultos espontaneamente ou por algum trauma. Apresentam uma taxa média de $25 \%$ de incidência e de $25 \%$ a $50 \%$ de recorrência após tratamento clínico, e geralmente cronificam, a cicatrização das úlceras ocorre lentamente e o tratamento é prolongado e difícil (12-26).

Um dos participantes sofreu AVC isquêmico aos cinco anos de idade e ficou com uma deficiência no braço como sequela. A causa mais comum de AVC na infância é a anemia falciforme e os maiores índices concentramse nas crianças de 2 a 5 anos de idade (27). Sendo evidenciado também nos estudos (28) que em crianças 
com AF é maior a incidência de AVC isquêmico, com uma incidência de mais de 280 vezes em relação a população pediátrica geral.

\subsection{O Fator Trabalho na Vida dos Falcêmicos}

O trabalho é uma atividade crucial para manutenção do bem-estar do corpo, da mente e da saúde dos indivíduos. Os pacientes com AF possuem restrições físicas por causa da doença e a maioria deles encontra dificuldades para se inserir no mercado de trabalho, como elucidados nas falas a seguir:

De trabalhar e tocar que é o meu sonho. (Gato)

Só mesmo a questão do trabalho que ele não consegue trabalhar. (Pêssego)

Em todos os relatos o fator desemprego foi apontado como um sério problema na vida das pessoas com AF, mesmo existindo outros tipos de limitações relacionadas à cronicidade da doença. A baixa ascendência nos estudos durante a infância e adolescência somada às diversas complicações provenientes da própria doença com o passar dos anos favorecem drasticamente para ausência de trabalho como atividade comum e prazerosa no cotidiano desses. Há uma grande dificuldade para conseguir emprego e, mesmo que consigam, não podem submeter-se a qualquer tipo de ocupação.

A AF deve ser considerada um problema de saúde pública por ser uma doença hereditária de maior prevalência no Brasil, mas também por interferir na vida escolar de $28,7 \%$ e na vida profissional de $62,5 \%$ dos portadores, o que gera dependência financeira dos responsáveis ou do Estado. O baixo nível educacional aliado à renda familiar depreciada pode ocasionar uma série de dificuldades, como a falta de trabalho, e quando encontram sentem-se impossibilitados por causa do acometimento provocado pela AF (20).

\subsection{Discriminação e Anemia Falciforme}

Esta categoria refere-se à percepção dos sujeitos da pesquisa de experiências, nas quais se tornaram vítimas de algum tipo de preconceito. Em suas respostas podese observar que os portadores deste estudo já sofreram discriminação social, devido aparência física, como também preconceito institucional durante assistência à saúde, como está evidenciado nas consequentes falas:

[...] Ele teve AVC na idade de cinco anos e o preconceito é sobre a deficiência (no braço) que ficou, né? Um pouquinho deficiente, as pessoas as vezes zombam muito, as vezes a pessoa não entende e diz aleijado e ele se sente mal. (Morango)

As pessoas tem preconceito assim, às vezes, nos hospitais, as pessoas ficam com aquela, assim, com preconceito mermo é, na Secretaria de Saúde. (Uva)

Os motivos da discriminação vivida pelos participantes da pesquisa, que também pôde ser percebida pelos seus familiares, concentram-se nas morbidades consequentes da AF e no desconhecimento de informações fidedignas sobre a patologia, o que leva a consentimentos errôneos sobre a doença e colabora para a prática do preconceito institucional.

A AF causa sérios acometimentos físicos e seus portadores enfrentam dificuldades para conviver com a doença em seus aspectos orgânicos como também em suas alterações de caráter psicológico e social (20). O desconhecimento do real conceito e principais características da doença reforça estereotipias e contribui para limitar a inserção e permanência de portadores de AF nos grupos sociais, como no ambiente escolar, que é de fundamental importância para formação da personalidade e manutenção das relações sociais dessas pessoas (29).

O racismo institucional sofrido, não raramente, pelas pessoas com AF ocorre por uma série de fatores, os quais abrangem aspectos socioeconômicos, raciais e relacionados com a condição crônica da patologia. Em consonância, o estudo (30) relata que a maioria das pessoas com doença falciforme, além de pertencer à classe economicamente desfavorável, constantemente é submetida aos efeitos da discriminação institucional, o que dificulta o acesso aos serviços de saúde e a qualidade no atendimento integral e equânime a essas pessoas.

\section{Conhecimento dos Familiares sobre Anemia Falciforme}

Nesta categoria aborda-se sobre o nível de conhecimento que os familiares possuem, já que são os principais cuidadores dos doentes e, portanto integrantes fundamentais na prevenção de complicações e identificação precoce das CVO. Percebeu-se que os entrevistados conhecem pouco ou nada sabem sobre a $\mathrm{AF}$, como descrito nas falas a seguir:

Eu entendo quase nada porque esse problema de anemia apareceu de um tempo pra cá. Eu entendo assim, cuidar, pra vê se Deus ajuda que fica boa. (Maçã)

Minha fia, eu não entendo, só entendo que é um sofrimento que só Jesus, só. (Uva)

Os trechos citados revelam a ausência de informações importantes sobre a doença e fundamentais para ministrar adequadamente os cuidados com os portadores. Não demonstram saber que a AF é incurável, os principais sintomas que podem ocorrer, o que devem evitar para prevenção de CVO, seguindo apenas o tratamento médico sem cuidados adicionais.

A família esclarecida sobre a doença modifica atitudes e diminui a ansiedade permitindo uma relação mais harmoniosa e terapêutica para com a saúde das pessoas, sendo assim, a relação com a pessoa doente pode ser preservada e é possível chegar a bons resultados mesmo em situações clínicas difíceis (5). 


\section{CONCLUSÕES}

Os portadores encontram obstáculos de natureza psicológica e social que somados com a condição crônica da patologia alteram sua qualidade de vida, evidenciando-se que certos fatores sociais e econômicos interferem na qualidade de vida das pessoas com anemia falciforme, tendo o desemprego como um dos fatores mais impactante em suas vidas e contribuindo negativamente para a insatisfação em relação a qualidade de vida desses sujeitos.

Outros entraves, também significativos e que diminuem a qualidade de vida, foram relatados pelos entrevistados como alterações em momentos de lazer provocadas pela progressão da doença, o que faz experimentar sentimentos de impotência e desconforto em suas relações sociais; dificuldades no acesso ao tratamento, enfrentando viagens longas e submetendo-se aos serviços que o SUS oferece, mesmo com suas falhas; infecções constantes que os obrigam a se expor à vários procedimentos cirúrgicos ao longo de suas vidas, além das úlceras de MMII que, muitas vezes, são inevitáveis.

Apesar de conviverem com variadas limitações em seu cotidiano pôde-se perceber, de maneira geral, que os participantes deste estudo mantêm uma boa relação social tanto com a família como com os amigos o que contribui positivamente para a qualidade de vida desse grupo. A Anemia Falciforme é uma doença hereditária e incurável, no entanto com o diagnóstico precoce, tratamento e cuidados adequados há possibilidades em aumentar a expectativa e qualidade de vida.

Para tanto se faz necessário que os profissionais de saúde conheçam e sejam habilitados para proporcionarem um atendimento holístico e equânime. Como também é fundamental que os familiares cuidadores sejam esclarecidos sobre a doença nos aspectos referentes à prevenção de complicações, ao reconhecimento precoce das CVO, das especificidades na alimentação, de manutenção constante da hidratação, dentre outras questões, enfatizando a importância da colaboração dos familiares no tratamento e elevação da qualidade de vida desses indivíduos.

Os aspectos psicossociais de toda doença crônica, inclusive da AF, merecem atenção redobrada com o intuito de evitar transtornos adicionais na qualidade de vida do doente, além dos que são inevitáveis com a evolução das manifestações físicas e clínicas da própria enfermidade.

Esta pesquisa demonstra a necessidade de (re) construção de medidas efetivas para o controle de desordens psicossociais que interferem negativamente na qualidade de vida dos portadores de AF. Vale ressaltar que existem poucos trabalhos com este enfoque e que outras pesquisas devem ser realizadas com o objetivo de contribuir para o entendimento das reais precisões e melhor qualidade de vida dos portadores de AF.

\section{REFERÊNCIAS BIBLIOGRÁFICAS}

1. Brasil. Ministério da Saúde. Agência Nacional de Vigilância Sanitária. Manual de diagnóstico e tratamento de doenças falciformes. Brasília, 2002.

2. Brasil. Ministério da Saúde. Manual de Educação em saúde. Linha de cuidado em doença falciforme. Brasília, 2009.

3. Cançado RD, Jesus JA. A doença falciforme no Brasil. Rev Bras Hematol Hemoter 2007; 29 (3): 204-6.

4. Ducattii RP, Teixeira AEA, Galão HA, Bonini-Domingos CR, Fett-Conte AC. Investigação de hemoglobinopatias em sangue de cordão umbilical de recém-nascidos do Hospital de Base de São José do Rio Preto. Rev Bras Hematol Hemoter 2001; 23 (1):23-9.

5. Guimarães TMR, Miranda, WL, Tavares MMF. O cotidiano das famílias de crianças e adolescentes portadores de anemia falciforme. Rev Bras Hematol Hemoter 2009; 31 (1): 9-14.

6. Roberti MRF, Moreira CLNSO, Tavares RS, Borges Filho HM, Silva AG, Maia CHG et al. Avaliação da qualidade de vida em portadores de doença falciforme do Hospital das Clínicas de Goiás, Brasil. Rev Bras Hematol Hemoter 2010; 32(6): 449-54.

7. Brasil. Ministério da Saúde. Secretaria de Atenção à Saúde. Departamento de Atenção Especializada. Manual de Eventos Agudos em Doença Falciforme. Brasília, 2009.

8. Loureiro MM, Rozenfeld S. Epidemiologia de internações por doença falciforme no Brasil. Ver Saúde Públ 2005; 39(6): 943-9.

9. Figueiredo MS. Aspectos psicossociais da anemia falciforme. Rev Bras Hematol Hemoter 2010; 32(3): 194.

10. Instituto Brasileiro de Geografia e Estatística [homepage na internet]. Censo Populacional, 2010. [Acesso Em 10 Maios 2012]. Disponível em: http://www.ibge.gov.br/cidadesat/xtras/perfil.php?codmun=292630\&r

11. Bardin L. Análise de conteúdo. Edições 70. Lisboa; 2009. 
12. Martins PRJ, Moraes-Souza H, Silveira TB. Morbimortalidade em doença falciforme. Rev Bras Hematol Hemoter 2010; $32(5): 378-83$.

13. Felix AA, Souza HM, Ribeiro SBF. Aspectos epidemiológicos e sociais da doença falciforme. Rev Bras Hematol Hemoter 2010; 32(3): 203-8.

14. Batista A, Andrade TC. Anemia Falciforme um problema de saúde pública no Brasil. Universitas Ciências da Saúde. 2008; 3 (1):83-99.

15. Brasil. Ministério da Saúde. Manual de Educação em Saúde: Autocuidado na Doença Falciforme. Brasília, 2009.

16. Lobo C, Marra VN, Silva RMG. Crises dolorosas na doença falciforme. Rev Bras Hematol Hemoter 2007; 29 (3): 247-58.

17. Brasil. Ministério da Saúde. Portaria GM/MS no 822, de 6 de Junho de 2001: Institui no âmbito do Sistema Único de Saúde, o Programa Nacional de Triagem Neonatal/PNTN. Diário Oficial da União, Brasília (DF) 2001; 33(2).

18. Bandeira FMGC. Triagem familiar ampliada para o gene da hemoglobina S. [tese] Recife: Departamento de Saúde Coletiva, Centro de Pesquisas Aggeu Magalhães Fundação Oswaldo Cruz; 2006.

19. Silva DG, Marques IR. Intervenções de enfermagem durante crises álgicas em portadores de Anemia Falciforme. Rev. bras. enferm. 2007; 60(3): 327-330.

20. Pitaluga WVC. Avaliação da Qualidade de Vida de Portadores de Anemia Falciforme. Goiana (GO); 2006.

21. Cordeiro RC, Ferreira SL. Discriminação racial e de gênero em discursos de mulheres negras com anemia falciforme. Esc. Anna Nery Rev. Enferm. 2009; 13(2): 352-358.

22. Silva RBP, Ramalho AS, Cassorla RMS. A anemia falciforme como problema de saúde pública no Brasil. Rev. Saúde Públ. 1993; 27(1): 54-8.

23. Friedrisch JR. Cirurgia e anestesia na doença falciforme. Rev Bras Hematol Hemoter 2007; 29 (3): 304-8.

24. Silva ALAL, Freire MAMS, Sabino Neto M, Garcia EB, Ferreira LM. Qualidade de vida após tratamento cirúrgico da assimetria mamária primária. Scienta Médica. 2007; 7(1): 9-13.

25. Dinuzzo DVP, Fonseca SF. Anemia falciforme e infecções. J. Pediatr. 2004; 80(5): 347-54.

26. Paladino SF. Úlcera de membros inferiores na anemia falciforme. Rev Bras Hematol Hemoter 2007; 29 (3): 288 90.

27. Ângulo IL. Acidente vascular cerebral e outras complicações do sistema nervoso central nas doenças falciformes. Rev Bras Hematol Hemoter 2007; 29(3): 262-67.

28. Filho EM, Carvalho WB. Acidentes vasculares encefálicos em pediatria. J. Pediatr. 2009; 85(6): 469-79.

29. Carvalho. ALO. Qualidade de vida de mulheres negras com anemia falciforme: implicações de gênero [dissertação]. Salvador: Escola de Enfermagem, Universidade Federal da Bahia; 2010.

30. Araújo PIC. O autocuidado na doença falciforme. Rev Bras Hematol Hemoter 2007; 29(3): 239-46. 